\title{
台湾地区农地政策的演进及其借鉴意义
}

\section{The Evolution of Taiwan's Agricultural Land Policy and Its Implication}

摘要: 农地在台湾经济社会发展中扮演了重要角色。 本文回顾了台湾 1949 年以来的农地政策变迁, 聚焦于 “农地农有农用”转变为“农地农用”的政策进程，将 台湾的农地政策划分为若干阶段，分析各阶段的演进 关系; 并讨论政策实施过程中产生的问题, 包括农地 租货、大量农舍兴建、休闲农业与民宿质量等; 最后 探讨了台湾农地政策演进的借鉴意义。

Abstract: Based on roles of agricultural land in different social and economic development phases, this paper reviews Taiwan's agricultural land policy since 1949. To be different from the literature with the view point of agricultural development, we separate different phases of agricultural land policies according to the evolution of agricultural land policies from agricultural land using for agriculture and owning by farmer to agricultural land only necessarily using for agriculture. By analyzing the relationship between the phases, the agricultural land problems caused by the agricultural land policies including land tenancy, agricultural cottage and leisure agriculture and $\mathrm{B} \& \mathrm{~B}$ are presented. Then some suggestions about the policies are discussed.

关键词: 台湾; 农地政策; 演进; 农地农用

Keywords: Taiwan; Agricultural Land Policy; Evolution; Agricultural Land Use

本成果得到中国人民大学 “985 工程”的支持
引言

农地作为农业生产的载体，其政策演进与农业发展息息相关。对台 湾而言, 其早期的农业政策与国民党政府迁台时的政治经济形势有关。 1949 年以后, 为了满足军需及岛内人口激增的粮食需求, 台湾当局为粮 食增产紧急实施私地减租政策, 并处理当时严重的业佃冲突问题 ${ }^{[1]}$ 。此外, 依据 “宪法” 规定, 农地政策以扶植自耕农为基本原则, 因此 1950 年代 推行的第一阶段土地改革, 以保护佃农权益与农地资源为主, 严格施行 农地农有及农地农用政策。在长期扶植自耕农的政策下, 台湾的农地逐 渐变得细碎, 于是政府在 1980 年代推动了第二阶段的土地改革, 出台了 “农业发展条例” 以及“农地重划政策”, 推行农场共同、委托及合作经 营。2000 年后, 随着经济产业结构的调整、农村劳动力的日益缺乏, 加 之农地产值低迷, 政府将政策的重点转移到提高农产品竞争力及维护生 态环境方面, 大力推进所谓的 “生产、生活与生态” 三生一体的现代化 农业发展 ${ }^{[2]}$ 。

按照台湾地区学者多年的研究以及“行政院农业发展委员会”印行的 “农业政策白皮书”的划分方法, 台湾农地政策的发展历程可分为五个阶 段 : 台湾光复初期至农地改革完成时期、以农养工时期、农工并重时期、 三生农业时期和农业活化与转型时期 ${ }^{[3]}$ 。这样划分的依据主要是农业的发 展阶段, 但如果从农地的角度来划分, 则可以概括为“农地农有农用”转 变为 “农地农用” 政策, 由此可以将农地政策划分为三个发展阶段, 分别 是实现“耕者有其田” 的土地改革阶段, 从“以农养工”到“农地保护” 阶段, 从“农地农有农用”转型为“农地农用”阶段。

从空间范围来看, 按照台湾的土地使用管制分区, 农地编列于都市土 地和非都市土地之中。依据 “区域计划法”，非都市土地划分为 11 种使用 分区及 19 种使用类别, 其中农地 ${ }^{1}$ 包括都市计划农业区、保护区, 以及非

作者: 施昱年, 中国人民大学公共管理学院土地管理系, 副教授

廖林超 (通信作者), 清华大学建设管理系, 副教授。pinchao@tsinghua.edu.cn

(1) 非都市土地内的特定农业区、一般农业区、山坡地保育区和森林区内的农牧用地, 又称为耕地, 耕地也是农地。 
都市土地的农牧用地、林业用地、养殖用地、水利用地、生 态保护用地及 “国土” 保安用地, 其开发利用受到农地政策 约束。

\section{1 实现 “耕者有其田” 的土地改革阶段}

1949-1952 年是台湾地区的第一次土地改革阶段。这 一时期, 国民党政府刚刚迁到台湾, 农业生产的主要目的是 粮食产出, 因此农业政策相对比较单一, 重点在于通过农地 政策促进农产品的生产。概括而言, 这一阶段的农地政策有 以下特征。

\section{1 平均地权是农地政策的核心思想}

台湾农地政策的核心思想是平均地权。按照孙中山的 农地思想, 土地要地尽其利, 必先平均地权; 平均地权是均 权制的土地所有制，政府具有上级所有权，人民分享下级所 有权, 以私有权的形式存在, 故平均地权不主张土地收归政 府所有, 而是通过规定地价、照价征税、照价收买以及涨价 归公四大手段实现均权 ${ }^{[4]}$ 。在孙中山思想的影响下, 台湾的 土地制度实行 “农地农（民）有、市地市（民）有、富源地 “国” 有”的平均地权思想 ${ }^{[5]}$ 。

\section{2 改革租佃制度, 解决土地分配和生产矛盾}

为实现平均地权、农地农（民）有，这一阶段农地政策 的主要目的是解决三个问题 : 第一, 当时大地主垄断土地所 有权, 拥有大量的土地, 造成大批佃农的存在; 第二, 当时 “法 律” 没有限制佃农交给地主的租金上限, 导致过高的佃租影 响了佃农的生计, 也影响了佃农对再生产的资本投人, 生产 力维持在较低水平, 因此必须改革租佃制度; 第三, 要提高 单位农地的产量 ${ }^{[6]}$ 。

\section{3 政府推动, 实现耕者有其田}

农地政策改革首先是要确保产量增加, 然后使增产的 利益归于大多数农民, 再逐步实现 “耕者有其田” 的最终 目的 ${ }^{[7]}$ 。1949 年 4 月 15 日台湾当局颁行 “台湾省私有耕地 租用办法”, 规定 “耕地租额不得超过主要作物全年收获总 量的 375\% , 原约定地租超过 375\% 者, 减为 375\% ; 不及 此数者, 不得增加”。租佃期限不得少于 6 年, 且在租约存 续期间, 地主除非有 “法定” 原因, 否则不得任意终止租 约, 并要求期满自动续约。375 减租政策缓解了长久以来地 主与佃农之间的紧张关系, 但并未完全解决地主与佃农的冲 突。作为最大 “地主” 的 “国民政府”, 只能从自身做起 ${ }^{[1]}$;
于是从 1951 年 6 月起, 以“台湾省放领公有耕地扶植自耕 农实施办法” 为依据, 政府将战后从日本手中接收的农地放 领给现耕农、雇农、佃农及半自耕农, 地价偿还期为 10 年, 分 20 期偿还。直到 1965 年政府才以兴建公共设施为由, 停 止办理农地放领。

“耕者有其田”是农地改革的最终目标。政府规定地主 仅能保留其出租水田三甲 ${ }^{1}$ （或其他等的水旱田）; 如果依 公告标准折算的甲数超出此限制, 且为租佃下的耕地, 则耕 地由政府强制征收, 转放给现有农户承领, 政府给地主配发 实物土地债卷七成和公营事业股票三成 ${ }^{[8]}$ 。此举将土地资本 移转到了工商业发展领域, 以投资带动经济发展 ${ }^{[9]}$ 。经过此 轮农地改革, 台湾 $83 \%$ 的出租土地变成了自耕土地, 由此 便提高了农业的生产力和农民的收人, 推动了台湾从农业地 区向工业化地区的转变 ${ }^{[10]}$ 。

\section{2 从“以农养工”到“农地保护”阶段}

1953-1990 年间的农地政策完成了从初期的“以农养 工”到“农地保护”的转变。其中, 1953-1968 年的农地 政策主要是支持工业发展, 实施每四年一轮的经济建设计划, 共计实施了四次, 这期间对农地保护较为忽视；1970 年代 之后, 由于农村生态环境的恶化愈加凸显, 农地保护逐渐受 到重视。

\section{1 初期 : 主要支持工业发展}

1950 年代起, 台湾开始实施“以农业培养工业、以工 业发展农业”政策。一方面，重视农业技术改进、作物制 度改善、耕地利用高度集约化、新品种引进, 以达到粮食 自给自足; 另一方面, 积极简化农业用地变为工业用地的 程序, 以推动区域经济发展。1960 年为进一步提供工业用地, 台湾当局颁布 “奖励投资条例”。援此条例, 由 “经济部” 确认, 县市政府如为创办工业或扩展原有工业（第 29 条）, 或是为增辟必要道路等特定需要, 均可将相关农地变更为 工业等用地 ${ }^{[11]}$ 。

\section{2 后期 : 农地保护意识增强}

“国民政府”迁台以后，土地利用缺乏总体谋划，加之 相关制度建设的滞后, 造成大量农地转为工业用地, 严重破 坏了生态环境, 影响了居民的生活质量 ${ }^{[12]}$ 。1970 年代的两 次石油危机, 其影响波及到了国际粮价, 台湾地区的粮食价 格也随之上涨。

多方面因素唤起了保护农地意识。1969 年台湾当局颁

(1) 一甲为 $9699.22 \mathrm{~m}^{2}$ 
布“农业政策检讨纲要”, 首先是扩大农场经营规模, 配合 农地重划（1960 年起开始实施）, 推行农业机械化, 促进粮 食作物和特用作物的增产, 同时改革农业金融制度, 充裕低 利资金; 其次，林地与山坡地在保育的前提下才能开发利用。 1973 年颁布 “实施都市计划以外地区建筑物管理办法”, 第 一条即规定：“维护优良农地, 确保粮食安全……”。同年 还颁布“农业发展条例”, 主要目的是保护农地, 限制农地 分割及移转为共有, 限制扩大经营规模, 限制农地的非农 业使用。为进一步管制农地非法使用，1974 年颁布“区域 计划法”, 直辖市或县 (市) 政府按 “非都市土地使用分 区计划”, 制定非都市土地使用分区图, 划定使用分区及 编定使用地实施管制。1976 年还出台了 “非都市土地使用 管制规则”。至此, 台湾地区的农地变更及使用管制实现 了“法制化”。

1982 年台湾开始推行第二阶段的农地改革, 在农地保 护意识增强的基础上, 积极推进农业现代化。措施包括 :

（1）提供扩大经营规模之购地贷款；（2）推行共同委托 与合作经营; (3) 加速农地重划; (4) 加快农业机械化;

（5）检讨修订 “法规” 并推动农地利用区域规划 ${ }^{[2,3]}$ 。

\section{3 从“农地农有农用”到“农地农用”阶段}

1990 年台湾地区申请加人关贸总协定 (GATT), 同 时希望加人世界贸易组织（WTO）。然而, 加人 GATT 和 WTO 后, 台湾必须逐步放开对外的农产品进口; 相对应的, 也必须解除对内部的农业保护补贴政策。因此, 一波推动 农地活化的讨论出现。特别是 1990 年后在野势力不断壮 大, “立法”上的争辩更趋激烈, 农地保护政策开始出现 松动。

\section{1 农地变更的规制松绑}

1995 年台湾当局为振兴经济, 核定实施《农地释出方 案》(以下简称《方案》)。《方案》实施的重点为: 扩大农 地变更通道、农业用地分区调整、放宽农地变更限制、简 化审查程序。对农地的释出施以总量管制, 从需求侧估计 至 2011 年约需释出农业用地 4.8 万 $\mathrm{hm}^{2}$, 长期可供变更面 积约达 16 万 $\mathrm{hm}^{2}$ 。《方案》依使用分区的差异将农地分为四
类: 第一类是都市计划农业区一一只要符合总体规划, 就 可以变更为非农业使用；第二类是非都市土地乡村区、工 业区和风景区内的农业用地一一可以依分区性质变更为非 农业使用; 第三类是非都市土地一般农业区农地一一只要 开发计划符合各相关主管部门制定的规范, 可以依其所定 审核标准将农地变更为非农用地; 第四类是特定农业区一 为了实施政府重大建设计划、“行政院”核定的开发计划或 公共设施建设、居住社区及低污染的工业区开发, 可以将 农地变更为非农土地。

\section{2 放宽农地农有、落实农地农用政策}

在农地开放思潮的影响下, 农民希望对 1983 年版的“农 业发展条例” 进行修正, 尤其针对农地分割、移转限制及农 舍兴建等。反对开放农地自由买卖的群体多认为管理不良会 造成农地的严重炒作 ${ }^{[13,14]}$; 同时还强调, 相关部门必须加强 农民身份与自耕能力的认定, 维持农地农有农用政策 ${ }^{[15,16]}$, 或至少确保农地农用 ${ }^{[17]}$; 赞成农地自由买卖的群体则认为台 湾在加人 WTO 之后, 如果农业保护政策取消, 应该开放农 地自由买卖, 放宽农地转用限制, 活化农业生产 ${ }^{[18,19]}$, 并在 增加农地使用效益、农地流动性以及防堵财团掮客的寻租行 为的情况下, 开放农地自由买卖 ${ }^{[20]}$ 。

1996 年 7 月 “行政院” 通过了“农业发展条例” 修正 案, 并经 “立法院” 讨论。该修正案也被称为 “第二次土地 改革” ${ }^{[2,3]}$ 。在修正前, 农地买卖双方和农舍兴建者均须具备 农民身份, 且对农地分割和共有有严格的限制 ${ }^{1}$; 实际上这 些规定已不符合当时小农户已经扩大的现实情况。2000 年 修正后的“农业发展条例”及 “土地法”正式颁布, 农地政 策由“农地农有农用”调整为“放宽农地农有、落实农地农 用”。在农地买卖部分, 开放自然人可购买、赠与或继承农地, 但农地必须从事农业使用; 此外还确立了买卖的程序, 放宽 了农地租赁和农地分割的管制要求 ${ }^{2}$ 。

\section{4 农地政策实施下的农地问题}

农地管理政策由“农地农有农用”调整为“农地农用”, 是自施行耕地 375 减租、公地放领及耕者有其田等政策以来 的最大变革。调整为“农地农用”的目的是为了以农地管理

(1) 根据修正前“农业发展条例” 第 30 条规定, “每宗耕地不得分割或移转为共有, 但因出售予毗邻耕地自耕农而与其耕地合并者, 得为分割, 因 继承而移转者, 得为共有, 共有耕地每人持分达 $5 \mathrm{hm}^{2}$ 以上且有分割必要者, 得报经省市主管机关核准分割为单独所有。”此即表明, 每宗共 有耕地每人持分面积达 $5 \mathrm{hm}^{2}$ 以上始能分割。

(2) 在农地租赁部分, 第 20 条规定, 2000 年 1 月 4 日之后签订的农地租货契约, 不适用 375 减租。在农地分割部分, 分割的最小面积限制, 由原 规定的共有耕地每人持分面积达 $5 \mathrm{hm}^{2}$ 始能分割, 降为分割后每人所有面积应达 $0.25 \mathrm{hm}^{2}$; 对现已共有的耕地, 则完全取消最小分割面积的限制。 在农舍部分，根据第 18 条，取得农业用地的农民，无自用农舍而须兴建者，经直辖市或县（市）主管机关核定，于不影响农业生产环境及农 村发展, 得申请以集村方式或在自有农业用地兴建农舍, 其在自有农业用地兴建农舍满五年始得移转, 但因继承或法院拍卖而移转者, 不在此限。 
取代所有权人资格限制, 并利于引进资金和技术。然而, 新 政实施以来也引发了许多农地管理的问题。

\section{1 “375 减租条例” 阻碍农地再利用}

375 减租实施至今已 60 余年, 许多承租农地的佃农已 传至第二代, 但在农地收人减少以及工商业就业机会增加的 情境下,许多佃农二代已将土地荒废。按照 “375 减租条例”, 若地主先提出解约须给予补偿金, 因此佃农多不愿主动解除 租约。

\section{2 大量农舍兴建侵占了农地资源}

“农业发展条例”同时放开农地自由买卖与农舍兴建, 造成许多自然人购买农地的目的并非在于农业经营, 而是休 闲享用, 这就导致了农舍林立一一实为别墅或民宿, 且因零 星建于田中, 不仅造成污染, 也影响到规模化耕作。以民宿 兴建较多的宜兰县为例, 2000-2014 年已兴建了 7612 栋农 舍 ${ }^{1}$, 造成大量农地流失。

\section{3 休闲农业与民宿质量良莠不齐}

为活化农地，台湾当局于 1992 年制定了“休闲农业区 设置管理办法”, 2000 年修正为 “休闲农业辅导管理办法”; 迄今休闲农业设施仍由农民自主建设, 这就造成了休闲农场、 民宿等的质量良莠不齐。虽然市场机制可以淘汰质量不佳的 休闲产品, 但农地一旦覆盖建筑, 再想还原为农地将付出巨 大的成本 (建筑拆除、土地整理、土壤修复、地力培养等)。 不佳的休闲产品实际上是在浪费土地。

\section{5 总结与借鉴}

台湾地区的农地政策在多年的实践中，已经基本完成其 各阶段的任务。其中, 最为成功的是实现 “耕者有其田” 的 土地改革。其后各阶段的农地政策演变也多是为了解决上一 阶段农地改革所遗留的问题, 可以对各个阶段的农地政策的 演进关系作如下总结。

第一阶段的土地改革致力于扶植自耕农、照顾弱势人群 及改善财富分配结构, 也兼顾了支撑工业发展。同时这一阶 段的平均地权政策造就了台湾农村的小农经济特点（或者说 是缺点)。首先, 基于农地报酬递减法则, 佃农在转为自耕 农初期, 的确有提高生产的意愿, 并能提高产量, 但长期来 看, 农业生产力仍然是报酬递减的; 其次, 战后持续增长的 农村人口也是导致农地分割越来越细碎的原因, 进而失去了

“规模经济间接带来的降低农业投资”的合理收益。因此,
第二阶段土地改革旨在解决土地细碎与收益下滑的问题。然 而, 快速的工业化进程导致农村年轻劳动力逐渐流失, 加之 政府限制农地自由买卖，使得农村既缺年轻人也缺资金，规 模化生产以及经济作物种植栽培便难以推进。基于此, 第三 阶段的土地改革主要是放松农地管制政策, 以吸引人们归农; 并引进资金和技术，以农业企业化及技术和经营创新，带动 农业升级。但由于农舍建设的管制不够严格，加上“休闲农 业辅导管理办法” 的副作用, 反而激励了很多企业或自然人 购买农地兴建农舍或休闲农场，违背了“立法”的初衷；加 之休闲农业的辅导机制不足，导致了部分休闲农业与民宿的 质量低下。

台湾地区的农村和农地状况与大陆有很多不同，但一些 问题有一定的相似性，因此前者的农地政策对后者有一定启 示意义。纵观台湾的农地政策演进, 初期对农地承租权的过 分保护, 使得承租者宁愿荒废土地, 也不愿主动退出租约, 间接导致了农地资源的浪费。其后对农地转换工业用地的规 制放松, 又导致了乡村非农产业的遍地开花, 加剧了农村土 地的破碎化, 也造成了环境污染。后期台湾当局鼓励建设农 业休闲设施促进了乡村旅游的发展, 呼应了台湾居民日益增 长的休闲需求。但是由于相关法规的不完善, 当局对于农村 地区的农舍兴建和民宿发展等的管制不够严格，造成了农地 被大量占用, 星罗棋布的田间建筑物不仅破坏了乡村景观, 也给规模化的农业生产造成更大不便。台湾当局的每次农地 政策改革都是为了解决之前农地改革遗留的问题, 但未能全 盘考虑农地改革可能带来的负效应, 亦即解决了旧问题、又 带来了新问题。这方面的经验教训值得大陆地区汲取。

当下大陆地区的农村正处于快速发展阶段, 农地政策的 改革一直在讨论之中, 譬如宅基地退出机制、流转机制、农 村集体经营性建设用地的买卖、农村休闲设施建设等。这些 政策的变革将产生非常深远的影响, 也并非是就事论事地应 对就能奏效。台湾地区的实践经验告诉我们, 农地政策改革 是一项复杂的系统工程, 需要缜密地设计。UP

本文得到上海市城乡规划学科高峰计划及 TJUPDI 和 $\mathrm{TJAD}$ 的支持，亦感谢赵民和张立老师对本文所做的工作。

\section{参考文献}

[1] 刘志伟, 柯志明. 战后粮政体制的建立与土地制度转型过程中的 “国 家”、地主与农民（1945-1953）[J].台湾史研究，2002, 9(1):107-180.

[2]“行政院农业委员会”、耕耘台湾农业大世纪农业纪实 [M]. “行政院农 业委员会”, 2013.

[3] 庄玉雯, 王玉真, 蔡彰辉.台湾之农地政策 [M]. 台北：中国土地政研 究所及土地改革训练所, 2010. 
[4] 周金声. 都市平均地权的实施 [M]. 台北 : 改造, 1954.

[5] 殷章甫. 台湾省实施耕者有其田之研讨 [M] / 萧铮, 编. 台湾土地及农 业问题资料. 台北：成文出版, 1981.

[6] 李宪文.台湾农地改革之实施及其绩效 $[\mathrm{M}] / /$ 李登辉, 编. 台湾农地改 革对乡村社会之贡献。台北: 李登辉出版, 1985 .

[7] 陈诚.如何实现耕者有其田 [M]. 台北: 正中, 1953.

[8] 于宗先, 王金利. 台湾土地问题：社会问题的根源 [M]. 台北：联经， 2001.

[9] “中央委员会秘书处”.中国国民党中央改造委员会会议决议汇编 [C]. 台北: 中国国民党, 1952 .

[10] 萧铮. 土地改革五十年: 萧铮回忆录 [M]. 台北: 中国地政研究所, 1980 .

[11] 许松根, 庄朝㭉.我国工业用地政策之探讨 [M]. 台北: “中央研究院经 济研究所”, 1991.

[12] 陈圣怡. 工业区的开发 [M]. 台北: 联经, 1982 .

[13] 陈明灿。农村地区农舍用地规划管理策略之研究 [M]. 台北: “行政院 农业委员会”，1998.
[14] 吴清辉。放宽农地农有与农地管理策略之研究 [M]. 台北: “行政院农 业委员会”, 1998.

[15] 刘健哲.农地移转管制政策之研究 [J]. 农业金融论丛, 1992, 28: 33100.

[16] 苏志超. 农地必须承受 “能自耕”与 “开放自由买卖”之讨论 $[\mathrm{J}]$. 人 与地, 1997, 161: 6-10.

[17] 姬世明.放宽农地所有权移转之探讨 [J]. 台湾地政, 1995: 110 .

[18]林国庆.台湾农地政策分析与政策建议 [J]. 经社法治论丛, 1994, 13:15-40。

[19] 邱茂英. 跨世纪农业政策新策略 $[\mathrm{M}]$. 台北：“行政院农业委员会”, 1996.

[20] 陈明灿。我国农地移转政策及利用问题之探讨：以政策被管制者之观 点为基础 [J]. 行政暨政策学报, 2000, 2: 97-146.

(本文编辑：王枫)

\section{$>>>$ 译者随笔 叶齐茂}

\section{广亩城市（上）}

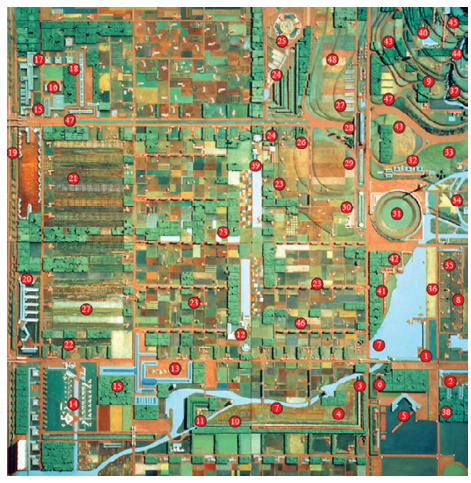

《广亩城市》的翻译稿已经交给编辑了, 这是赖特“未 来城市三部曲”的第二部。其实, 赖特这本书的原书名是 《民主建设城市之际》(When Democracy Builds, 芝加哥大 学出版社, 1945), 而在翻译完这本书之后, 我觉得这本书 的中文版书名还是应该从全书的具体内容出发, 使用《广亩 城市》作为书名, 可能会减少图书分类上的误判, 不至于因 为“民主”一词而把这本书归入“政治、法律”类。当然也 有可能避免误导那些依据书名选择读书的读者。按照这本书 的内容, 它应该归入“工业技术一建筑科学”类。

《广亩城市》是编制具有“广亩城市” 特征的社区总体 规划的设计纲要, 所以, 《广亩城市》实际上谈的是一种名 叫“广亩城市”的未来城市模式。
规划设计基础——广亩城市”应用总体分散化的规 划原则, 把所有的规划单元通过建筑方式重新整合成为一个 整体; “广亩城市”的居民通过使用和开发自己地块的方式, 保持相应地块的自由使用权; “广亩城市”的居民拥有“广 亩城市”的公用设施和政府; “广亩城市”的居民在自己土 地上所做的一切都是私人的, 他们或在自己土地上, 或在自 已的实验室里, 或在自己对外服务的办公室里, 用公正的手 段, 从事他们自己工作, 获得生计。

人口——这个名叫“广亩城市”的社区, 可以小到一个 自然村落, 大至整个国家。因为“广亩城市”的劳动者都是 兼业的, 一个职业为主, 兼顾其他职业, 或者说, “亦工亦 农亦商亦学亦官亦 $X^{\prime}$, 减少社会分工, 这样一来, 我们现 在使用的那些城市人口估算方法, 如劳动平衡法, 就不那么 好用了。实际上, 赖特并没有具体提出任何一个“广亩城市” 社区的人口规模指标。当然, 赖特制作了一个 “广亩城市” 的模型。这个模型包括的土地面积为 4 平方英里, 规划居住 人口约为 7000 人 (1400 家), 每家平均人口为 5 人或更多。

土地——广亩城市”采用“一英亩一家人”的基本用 地指标。不过, 这“一英亩地”并非都是“建设用地”, 更 不是全部用建筑物覆盖起来, 相反, 这“一英亩地”的绝大 部分用于农业、林业、养殖业或保持自然状态。国家掌握“广 亩城市”的土地。土地分配、土地开发, 与整体和谐相关的

(下转119页) 